\title{
Identifying, refining, measuring and analyzing the cost of quality (CoQ) (real case: a manufacturing firm)
}

\author{
Mohsen Cheshmberah ${ }^{1, *}$, Yadollah Asgari Savadjani ${ }^{2}$, Mehdi Karbasian $^{3}$ \\ ${ }^{1}$ Faculty of Management \& Industrial Engineering, Malek Ashtar University of Technology, Iran. \\ Corresponding author. mcheshmberah@mut.ac.ir \\ ${ }^{2}$ Alumnus of Management \& Industrial Engineering, Malek Ashtar University of Technology, Iran. \\ mcheshmberah@mut.ac.ir \\ ${ }^{3}$ Faculty of Management \& Industrial Engineering, Malek Ashtar University of Technology, Iran. \\ mkarbasi@mut-es.ac.ir
}

\begin{abstract}
This article is dedicated to identifying, screening and calculating quality costs items based on the traditional 'Prevention-Appraisal-Failure' (PAF) model in all four categories of prevention cost, appraisal cost, internal failure cost and external failure cost; for this purpose, the quality cost items are listed according to the BS 6143 standard, Juran's quality handbook and opinions of the experts; this list are refined using the Lawshe technique. In order to calculate the quality cost items in the four groups, formulas based on expert opinions have been developed and the quality cost items have been calculated and analyzed for two consecutive years.
\end{abstract}

Keywords: cost of quality (CoQ), P.A.F. model, BS 6143, Lawshe method, manufacturing firm.

\section{Introduction}

In order to improve quality, an organization must take into account the costs associated with quality since one of the goals of the improvement program is to reduce quality costs. In order to reduce quality costs, it is necessary to identify and measure quality costs [1].

$\mathrm{CoQ}$ is understood as the sum of conformance plus non-conformance costs, where cost of conformance is the cost paid for prevention of poor quality and defect(s) in products or services (as inspection and quality appraisal) and cost of non-conformance is the cost of poor quality (CoPQ) caused by product and service failure (as rework, returns and customer complaint). Identification, measuring, reporting and analysis the cost of quality (CoQ) is an important issue to achieve high quality.

Quality costs are not only an indicator of the quality level of a product/service, but also an indicator of how much to measure or increase a given level of quality. Quality costs are the costs of preventing, identifying and removing defects in materials, products, services, or processes, while any costs incurred due to poor quality [2] [3] [1]. To measure and anallyze quality costs of an organization needs to classify costs [1];

In previous research, several CoQ models have been presented which are: P-A-F model, Crosby's model, Opportunity or intangible cost model, Process cost model and ABC model. [3]. P.A.F. include four categories: prevention costs (costs of any action taken to investigate, prevent or reduce defects and failures, appraisal costs (costs of assessing the quality achieved, internal failure costs (costs associated with defects found before the customer receives the product/service), external failure costs (costs associated with defects found after the customer receives the product/service) [1] [4]. The quality costs in the P.A.F. model are as follows. 
Table 1: PAF Quality Cost Categories [4]

\begin{tabular}{|c|c|c|c|}
\hline Types & Description & Samples \\
\hline $\begin{array}{c}\text { Prevention } \\
\text { Cost }\end{array}$ & $\begin{array}{c}\text { Related to activities designed and trained to } \\
\text { guarantee good quality and prevent poor } \\
\text { quality in services or products }\end{array}$ & $\begin{array}{c}\text { Process design/change, Quality education and } \\
\text { training, Knowledgeable human resource } \\
\text { recruitment, Preventive maintenance, New } \\
\text { product review }\end{array}$ \\
\hline $\begin{array}{c}\text { Appraisal } \\
\text { Cost }\end{array}$ & $\begin{array}{c}\text { Related to measuring or inspecting services or } \\
\text { products to achieve performance requirements } \\
\text { and quality standards }\end{array}$ & $\begin{array}{c}\text { Sampling and measurements, Evaluations and } \\
\text { assessments, Problem analysis, In-process and } \\
\text { final inspection/test, Product or service audits } \\
\text { and detection }\end{array}$ \\
\hline Failure & Internal & $\begin{array}{c}\text { Affected by products or services } \\
\text { not conforming to customer/user } \\
\text { needs and are identified before } \\
\text { delivery }\end{array}$ & $\begin{array}{c}\text { Retesting, Rework and Repair, Unscheduled } \\
\text { and unplanned service, Defect removal, Lost } \\
\text { process time/Delay and shortages }\end{array}$ \\
\cline { 2 - 4 } & External & $\begin{array}{c}\text { Affected by deficiencies which are } \\
\text { found after delivery of services or } \\
\text { products to external customers, } \\
\text { which causes customer to be } \\
\text { dissatisfied }\end{array}$ & $\begin{array}{c}\text { Complaints/Liability claims, Repairing goods } \\
\text { and redoing services, Losses due to sales } \\
\text { reductions, Warranties, Returned products and } \\
\text { customer's bad will, Poor safety/availability }\end{array}$ \\
\hline
\end{tabular}

Some researchers like Tsai (1998), believe that measuring CoQ can be made more accurate by including overhead costs. This improvement could be implemented by activity-based costing (ABC) approach developed by Cooper and Kaplan. ABC approach concentrates on the accurate assignment of overhead costs to products [3] [5].

In the literature of quality costs, various researches can be seen. The following table summarizes some of the research on cost of quality (CoQ). Some researchers, such as Ramdeen et al. (2007), have specifically performed the calculation and analysis of quality costs in a particular firm; they have applied the cost of quality (COQ) concepts in a hotel restaurant environment using the P.A.F. model [6].

Table 2: A review of some published works

\begin{tabular}{|l|l|}
\hline \multicolumn{1}{|c|}{ Author(s)- Year } & \multicolumn{1}{c|}{ Description } \\
\hline Jeffery (2004) [7] & presenting a quality cost model \\
\hline Schiffauerova \& Thomson (2006) [8] & providing evidence of cost management \\
\hline Vaxevanidis et al. (2009) [1]. & literature review \\
\hline Antonaras et al. (2010) [9]. & quality cost measurement \\
\hline Tawfek et al. (2012) [10]. & Establishing a neural network model to assess cost of quality \\
\hline Arabian et al. (2013) [4] & Comparing different COQ models \\
\hline Omar \& Murgan (2014) [11]. & proposing a model for quantifying the cost of quality \\
\hline Sailaja et al. (2015) [12]. & making analysis to identify the hidden elements of quality costs \\
\hline Chatzipetrou and Moschidis (2016) [13]. & studying the CoQ of supermarkets in Greece \\
\hline Lee et al. (2016) [14]. & Establishing a CoQ management system for power generation firms \\
\hline Murumkar et al. (2017) [15] & Surveying the literature and models \\
\hline Teli et al. (2018) [16] & Analyzing the COQ in Indian auto industry \\
\hline Schmidt and Pearson (2019) [17]. & Developing methods to estimate the COQ errors \\
\hline
\end{tabular}

In this paper, the results of the study of quality costs in a manufacturing company are reported. The company specializes in designing and manufacturing customized parts for aerospace, automotive and other areas as a supplier.

To manage quality costs in the company, first a list of quality costs for all four categories of P.A.F. has been created; so, this list was refined and calculated according to the conditions of the company under study and the results were analyzed. The steps followed are described in the research methodology below.

\section{The research methodology}

The following steps have been taken to conduct the research and achieve its goals including identification, calculation and analysis of the quality costs in the industry under study. 


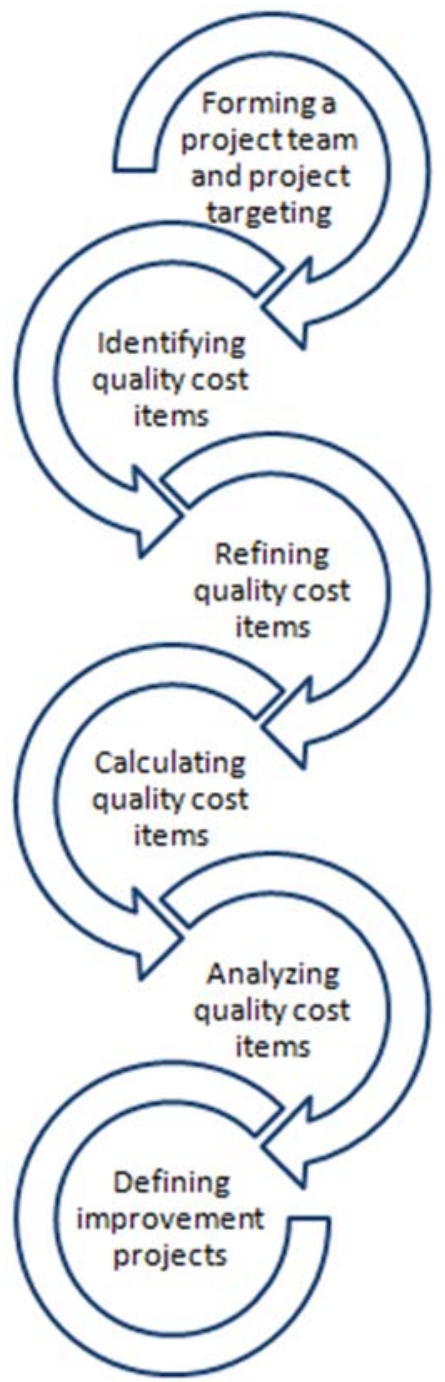

Figure 1: the steps of the research

The following steps have been taken to conduct the research and achieve its goals including identification, calculation and analysis of the quality costs in the industry under study:

\section{Step 1- Forming a project team and project targeting}

In the first step, the Quality Cost Management Project team was established as a multi-sectoral team with the management of the company's quality deputy consisting of representatives from various sectors of production, design and planning, sales and marketing, warehousing as well as quality. The purpose of the project was outlined and related plans were provided to cover the necessary information and resources. The important questions that were addressed during the initial project team meetings were as follows:

- Why is it necessary to identify and analyze the quality costs of the company? (Goal review)

- In which parts of the company will the project be implemented? (Implementation domain)

- At what time periods should the report be made? (Reporting timing)

- How and by which sectors should the information needed to calculate quality costs be provided? (Data and information supply)

- Which sections should prepare the report? (Reporter providers)

- Who and what parts of the company should be given the final results and analyses? (Issueing of results and analyses)

\section{Step 2- Identifying quality cost items}

In order to identify $\mathrm{CoQ}$ elements, some companies benchmark or borrow elements from other companies, which have established CoQ programs. However, it is recommended that costs be tailor-made for each organization [3]. 
The important point is that the quality cost components and examples are different in various companies and organizations, and not necessarily a fixed list of cost components will apply everywhere and these cost components must be tailored to each organization.

In this study the P.A.F. model is used to identify and analyze quality costs. Various sources such as the Juran's Quality Handbook [2] and BS 6143 standard [18] were used to identify quality cost items and to provide an initial list of cost items. Attached to this standard are examples of each of the four groups including costs of prevention, evaluation, internal failure and external failure. The initial list consisted of 166 cost items.

\section{Step 3- Refining quality cost items}

The initial list of quality cost components in all four cost areas should be refined and tailored to the requirements and conditions of the company under study. For this purpose, project team members were asked to rewrite the titles of project components as necessary, and then the list was refined using the Lauche method. In order to refine costs using the CVR index, project team members were asked to rate each quality cost item in three classes of being "essential", "useful, but not essential" and "not necessary" in their company. Continuation of the analysis was performed using CVR values and Lauche table. From the initial list of cost items (166 cost items) 68 items remained after refining. The following equation was exploited to calculate the content validity ratio (CVR) index [19]:

$$
C V R=\frac{n_{e}-n / 2}{n / 2}
$$

Where $n_{e}$ is the number of panel members who have identified the dimension or question as "essential" and $n$ is the total number of panel members. The minimum acceptable value of the table provided by Lawshe is as follows:

Table 3: The minimum acceptable CVR based on the number of scoring specialists

\begin{tabular}{cccccr} 
Number of Professionals & CVR & Number of Professionals & CVR & Number of Professionals & CVR \\
\hline 5 & 0.99 & 11 & 0.59 & 25 & 0.37 \\
6 & 0.99 & 12 & 0.56 & 30 & 0.33 \\
7 & 0.99 & 13 & 0.54 & 0.31 \\
8 & 0.75 & 14 & 0.51 & 0.29 \\
9 & 0.78 & 15 & 0.40 & & \\
10 & 0.62 & 20 & 0.42 &
\end{tabular}

After filling out the Lauche Method Questionnaire by project team members (10 members) and reviewing the results and considering cost items with CVR of greater than 0.62 , the list of quality cost items was obtained, examples of which are introduced in the following table. Also, according to calculations related to Cronbach's alpha test and entering questionnaire information in SPSS software, Cronbach's alpha value of 7.840 is obtained which is greater than 0.7 . As a result, the questionnaire is reliable and the internal consistency of the questions can be assured.

After the Lawshe's method questionnaire were completed by the 12 members of the panel, the CVR calculation results for the 15 dimensions in question were obtained as is expressed below. 
Table 4: Examples of refined cost items

\begin{tabular}{|l|}
\hline Examples of refined prevention cost items \\
\hline$\bullet \quad$ The costs of Quality training \\
\hline The cost of providing educational equipments \\
\hline The cost of out-of-organization training \\
\hline The trainers/consultants' fee \\
\hline$\bullet \quad$ The costs of design and manufacturing of measurement and testing equipments \\
\hline The costs of designing and manufacturing gauges \\
\hline The costs of preparing speciao laboratories \\
\hline The costs of purchasing/renting measurement and test equipments \\
\hline The costs of training required for use of measurement and test equipments \\
\hline \\
\hline Examples of refined appraisal cost items \\
\hline$\bullet \quad$ The costs of raw material test \\
\hline The costs of inspection of input items \\
\hline The costs of inspection (\& test) at supplier location \\
\hline The costs of testing of raw materials in the warehouse \\
\hline \\
\hline Examples of refined internal failure cost items \\
\hline • The costs of reworks and corrective actions \\
\hline The costs of reworking on modifiable defective items \\
\hline The costs of re-inspection after reworking \& corrective action \\
\hline \\
\hline Examples of refined external failure cost items \\
\hline$\bullet \quad$ The costs of after-sales services \\
\hline $\begin{array}{l}\text { The costs of transporting, handling and returning defevtive (nonconforming) products from } \\
\text { the customer's location to the factory }\end{array}$ \\
\hline The costs of customer complaints \\
\hline
\end{tabular}

Step 4- Calculating quality cost items

Each of the refined quality cost components has been carefully reviewed in the project team meetings, and in consultation with the company's finance experts and other experts in the project team, efforts have been made to formulate cost item calculations by proper definition of the parameters. The following table provides examples of cost components and their formulas. Also, table ... shows the parameter definitions. 
Table 5: The Parameters of computational formulas

\begin{tabular}{|c|c|}
\hline $\begin{array}{c}\text { Paramete } \\
\mathrm{r}\end{array}$ & Description \\
\hline A & The cost of educational equipments \\
\hline A15 & The rent of training location cost \\
\hline B15 & The cost of booklets \& pamphlets \\
\hline $\mathrm{C} 15$ & The cost of eating and drinking services \\
\hline $\mathrm{B}$ & The trainers' fee \\
\hline $\mathrm{C}$ & The overhead training costs (travel etc.) \\
\hline $\mathrm{D}$ & Hourly fee of teaching / consultation \\
\hline E & The hours of cource \\
\hline $\mathrm{F}$ & The average hourly wage for trainees \\
\hline $\mathrm{J}$ & The average hourly wage for involved staffs \\
\hline $\mathrm{L}$ & The cost of consumables \\
\hline $\mathrm{Z}$ & The man-hours spent for internal audit \\
\hline A1 & The man-hours spent for designing and manufacturing gauges \\
\hline B1 & The cost of gauges (material, testing, verification) \\
\hline I11 & The man-hours spent for inspection of input items \\
\hline $\mathrm{J} 11$ & The cost of out-of-organization tests for input items \\
\hline K11 & The man-hours spent for testing and inspection at supplier's place \\
\hline $\mathrm{C} 1$ & $\begin{array}{l}\text { The cost of equipping special laboratories (calculated based on depreciated service life for } \\
\text { the calculation period of quality costs such as monthly or annual) }\end{array}$ \\
\hline D1 & $\begin{array}{l}\text { The cost of purchasing (or renting) measurement and testing equipment (calculated based on } \\
\text { depreciated service life for the calculation period of quality costs such as monthly or annual) }\end{array}$ \\
\hline E1 & The trainer's fee for training the use of measurement and test instruments \\
\hline $\mathrm{R} 12$ & The man-hour spent for reworking of defective items \\
\hline $\mathrm{S} 12$ & The number of hours of the machine utilization for reworking \\
\hline $\mathrm{T} 12$ & The cost of one hour of the machine utilization for reworking \\
\hline V12 & The man-hours spent for reinspection (after reworking) \\
\hline $\mathrm{C} 14$ & $\begin{array}{l}\text { The man-hours spent for transporting, handling and returning defevtive (nonconforming) } \\
\text { products }\end{array}$ \\
\hline D14 & $\begin{array}{l}\text { The cost of shipping and returning the defevtive (nonconforming) products from the } \\
\text { customer's location to the factory }\end{array}$ \\
\hline $\mathrm{I} 14$ & The man-hour spent for customer complaints \\
\hline K14 & The costs of staffs traveling to the customer's location for customer complaints \\
\hline M11 & The cost of tests performed at supplier's location \\
\hline N11 & The man-hours spent for testing raw materials in the warehouse \\
\hline $\mathrm{O} 11$ & The cost of testing raw materials in the warehouse \\
\hline L11 & $\begin{array}{l}\text { The cost of traveling for inspection personnels and transporting measurement equipments to } \\
\text { supplier's location }\end{array}$ \\
\hline
\end{tabular}


Table 6: Examples of formulas for preventive cost items

\begin{tabular}{|l|c|}
\hline \multicolumn{1}{|c|}{ The costs of Quality training } \\
\hline The cost of providing educational equipments & $A+A 15+B 15+C 15$ \\
\hline The cost of out-of-organization training & $B+C$ \\
\hline The trainers/consultants' fee & $A+A 15+B 15+C 15$ \\
\hline & \\
\hline \multicolumn{2}{|l|}{ The costs of design and manufacturing of measurement and testing equipments } \\
\hline The costs of designing and manufacturing gauges & $(A 1 \times Z)+B 1$ \\
\hline The costs of preparing speciao laboratories & $C 1$ \\
\hline The costs of purchasing/renting measurement and test equipments & $D 1$ \\
\hline The costs of training required for use of measurement and test equipments & $(E \times F)+E 1$ \\
\hline
\end{tabular}

Table 7: Examples of formulas for appraisal cost items

\begin{tabular}{|l|c|}
\hline \multicolumn{1}{|c|}{ The costs of raw material test } \\
\hline The costs of inspection of input items & $(J \times I 11)+L+J 11$ \\
\hline The costs of inspection $(\&$ test $)$ at supplier location & $(J \times K 11)+L+L 11+M 11$ \\
\hline The costs of testing of raw materials in the warehouse & $(J \times N 11)+L+O 11$ \\
\hline
\end{tabular}

Table 8: Examples of formulas for internal failure cost items

\begin{tabular}{|l|l|}
\hline \multicolumn{2}{|l|}{ Examples of refined internal failure cost items } \\
\hline - The costs of reworks and corrective actions \\
\hline The costs of reworking on modifiable defective items & $(J \times R 12)+(S 12+T 12)$ \\
\hline The costs of re-inspection after reworking \& corrective action & $(J \times V 12)$ \\
\hline
\end{tabular}

Table 9: Examples of formulas for external failure cost items

\section{- The costs of after-sales services}

The costs of transporting, handling and returning defevtive (nonconforming) products from the customer's location to the factory

The costs of customer complaints

$(J \times C 14)+D 14$

$(J \times I 14)+K 14$

\section{Step 5- Analyzing quality cost items}

The data analysis from the calculations of the quality cost items is performed on the basis of table 10. ratios using Excel software. Also, quality cost trend analysis was performed for two consecutive periods.

Table 10: Symbols and formulas of CoQ and related ratios

\begin{tabular}{|c|c|}
\hline Cost title & Symbol / calculation \\
\hline Quality Costs (COQ) & $C O Q(=P C+A C+I F C+E F C)$ \\
\hline Company Annual Revenue (R) & $T R($ Total Revenue $)$ \\
\hline The ratio of total quality costs to annual revenue & $\frac{C O Q}{T R}$ \\
\hline
\end{tabular}

The costs and ratios of quality costs have been calculated for two consecutive periods, the results of which are presented in table 11 .

Table 11: The quantity and trend of quality costs

\begin{tabular}{|c|c|c|}
\hline Cost title & First year & Second year \\
\hline Quality Costs (COQ) & $131,413,363$ & $150,028,675$ \\
\hline Company Annual Revenue (R) & $777,593,864$ & $949,548,576$ \\
\hline The ratio of total quality costs to annual revenue & $\mathbf{0 . 1 6 9}$ & $\mathbf{0 . 1 5 8}$ \\
\hline
\end{tabular}


Based on the analyzes cited in some references, such as Kumar et al. (2018), the relationship between CoQ / R and the sigma level of process can be determined (below table). The ratios of both two years indicate the sigma level of corporate processes of around 4, which by focusing on reducing this ratio, the sigma level of corporate processes tending to six sigma.

Table 12: The relationship between $\mathrm{CoQ} / \mathrm{TR}$ ratio and sigma level [20]

\begin{tabular}{|c|c|c|c|c|}
\hline Sigma Level & $\begin{array}{l}\text { Defect Rate } \\
\text { (PPM) }\end{array}$ & Yield in \% & $\begin{array}{c}\text { Cost of Quality (\% of } \\
\text { sales) }\end{array}$ & Competitive Level \\
\hline 6 & 3.4 & 99.99966 & $<10 \%$ & \multirow{2}{*}{ World Class } \\
\hline 5 & 233 & 99.97670 & 10 to $15 \%$ & \\
\hline 4 & 6210 & 99.37900 & 15 to $20 \%$ & \multirow{2}{*}{ Industry Average } \\
\hline 3 & 66807 & 93.31930 & 20 to $30 \%$ & \\
\hline 2 & 308537 & 69.14620 & 30 to $40 \%$ & \multirow{2}{*}{ Non-competitive } \\
\hline 1 & 690000 & 31.00000 & $>40 \%$ & \\
\hline
\end{tabular}

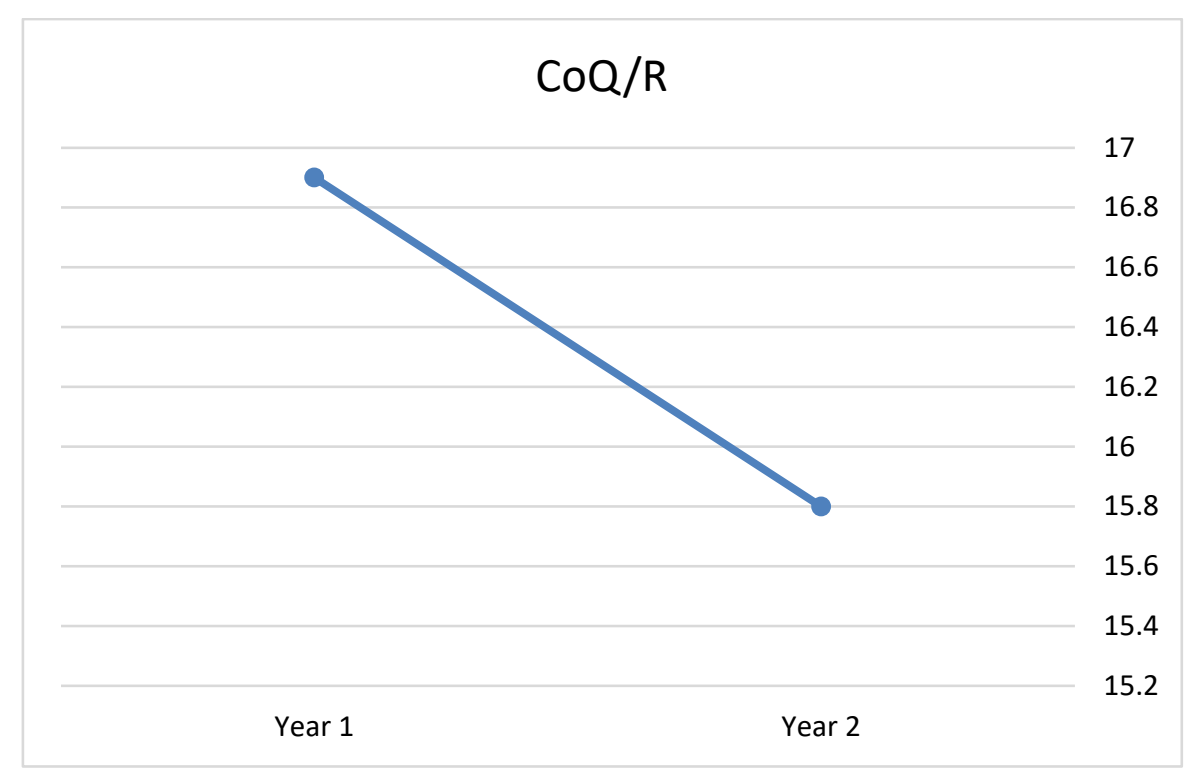

Figure 2: the trend of $\mathrm{CoQ} / \mathrm{TR}$ ratio in two consecutive years

The figure above shows the trend for the CoQ / TR ratio. This ratio has decreased during the first to second period (year), which is a valuable achievement. With further improvements, this ratio is expected to decline again in the subsequent periods. In fact, by increasing investment in prevention and appraisal costs, internal and external failure costs can be reduced.

\section{Step 6- Defining Improvement Projects}

Based on the results of the calculations and the analysis of quality costs, a set of improvement actions and projects are needed to reduce failure costs (nonconformance). The task of defining and leading improvement projects is the responsibility of the quality management sector of the company. Implementing of improvement projects are the responsibility of different sectors of the company in the form of cross functional teams (CFTs) or functional teams. In order to accomplish improvement projects in the company, there are three important steps:

- Forming the improvement project team

- Using improvement methodology like Deming Cycle (PDCA) (plan-do-check-act or plan-do-checkadjust)

- Finding the results and getting the end result (finalizing)

It is important for the company that the definition and implementation of improvement projects should never stop in order to improve quality and reduce nonconformance costs. 


\section{Conclusion}

In this paper, a list of quality cost items based on the P.A.F. was provided at a manufacturing company and refined by the Lawshe's method. The formulas were developed by the company experts to calculate the refined cost items, and then, the items of quality costs were calculated and analyzed for two consecutive years. The following measures are suggested to improve the quality and reduce the costs of poor quality (COPQs) in the company under study:

- Preparing and publishing quality cost reports in shorter than annual periods (such as semiannually)

- Creating quality cost management software to receive online information, automate related calculations, and monitor results and analyses by company experts and decision makers

- Investing and planning to expand preventive activities (using techniques like FMEA or Failure modes and effects analysis)

Also, two other important improvements should be made in the future on the quality management system of the company under study; firstly, there must be a mechanism to ensure the accuracy of the data and information provided by the various departments. Moreover, additional ratios and indices need to be considered for quality cost analysis in order to produce more accurate and effective analyzes.

\section{References}

[1] N. Vaxevanidis, G. Petropoulos, J. Avakumovic and A. Mourlas, "Cost Of Quality Models And Their Implementation In Manufacturing Firms," Int. Journal for Quality research, pp. V.3, N.1, 2009.

[2] J. M. Juran and A. B. Godfrey, Juran's quality handbook, 5th ed: McGraw-Hill, 1999.

[3] N. M. Vaxevanidis and G. Petropoulos, "A literature survey of cost of quality models," Journal of Engineering, 2008.

[4] T. Arabian, S. M. M. Jourabchi, Z. Leman and M. Ismail, "A Research on the Impact of Cost of Quality Models and Reporting System on Managing Cost of Quality," Int. Proceedings of Economics Development and Research, p. V.59, 2013.

[5] W. Tsai, "Quality cost measurement under activity-based costing," Int. Journal of Quality \& Reliability Management, pp. (15) 719752,1998

[6] C. Ramdeen, J. Santos and H. K. Chatfield, "Measuring the cost of quality in a hotel restaurant operation," Int. Journal of Contemporary Hospitality Management, pp. Vol. 19 No. 4, pp.286-295, 2007.

[7] A. B. Jeffery, "Managing Quality: Modeling the Cost of Quality Improvement," Southwest Business and Economics Journal, 2004.

[8] A. Schiffauerova and V. J. Thomson, "A review of research on cost of quality models and best practices," Int. Journal of Quality \& Reliability Management, 2006.

[9] A. Antonaras, C. Memtsa and M. Iacovidou, "The Challenge of Measuring the Cost of Quality," in 4th Annual Quality Congress Middle East, Dubai, 2010.

[10] H. S. Tawfek, H. E. H. Mohammed and M. E. Abdel Razek, "Assessment of the expected cost of quality (COQ) in construction projects in Egypt using artificial neural network model," HBRC Journal, pp. 8, 132-143, 2012.

[11] M. K. Omar and S. Murgan, "An improved model for the cost of quality," Int. Journal of Quality \& Reliability Management, 2014

[12] A. Sailaja, P. C. Basak and K. G. Viswanadhan, "Costs of Quality: Exploratory Analysis of Hidden Elements and Prioritization using Analytic Hierarchy Process," Int. Journal of Supply and Operations Management, 2015.

[13] E. Chatzipetrou and O. Moschidis, "Quality costing: a survey in Greek supermarkets using multiple correspondence analysis," Int. Journal of Quality \& Reliability Management, pp. V. 33, Iss.5, pp. 615 - 632, 2016.

[14] M. C. Lee, B. S. Hwang, S. J. Park, M. G. Kim, D. C. Kim and W. S. Shin, "A Research on the Development of Quality Cost Management System for Power Industry," Journal of Korean Social Quality Management, pp. Vol. 44, N.4: 713-733, 2016.

[15] A. Murumkar, S. Teli, U. M. Bhushi and A. S. Deshpande, "Hidden Cost of Quality: A Review," in 11th ISDSI International Conference, India, 2017.

[16] S. N. Teli, A. Murumar and P. Jadhav, "Cost of Quality for Automobile Industry: A Review," in 4th International Conference on Engineering Confluence, Mumbai, 2018.

[17] R. L. Schmidt and L. N. Pearson, "Estimating the cost of quality of errors in the analytical phase," Clinica Chimica Acta, p. 495: 60$66,2019$.

[18] B. S. Institution, "BS 6143: Part 2, Guide to Economics of Quality: Prevention, Appraisal and Failure Model," British Standards Institution, London, 1990.

[19] C. H. Lawshe, "a quantitative approach to content validity.," Personnel Psychology, pp. 28 (563-575), 1975.

[20] V. Kumar, P. Verma and V. Muthukumaar, "The Performances of Process Capability Indices in the Six-Sigma Competitiveness Levels," in Int. Conf. on Industrial Engineering and Operations Management, Bandung, Indonesia, 2018. 